\title{
Santrifüj Dekantör Helezonunun Sonlu Elemanlar Analizi
}

\author{
Gözde SARI ${ }^{1 *}$, Ahmet Alper AKIŞ ${ }^{1,2}$, Gökhan ÜĞ̈̈DÜCÜ³ \\ ${ }^{I}$ Manisa Celal Bayar Üniversitesi, Makine Mühendisliği Bölümü, Manisa \\ ${ }^{2} N U M E S Y S$ A.Ş., İzmir \\ ${ }^{3}$ HAUS Makine Sanayi A.S., Aydin \\ (ORCID: 0000-0002-0046-9090) (ORCID: 0000-0001-7458-6671) (ORCID:0000-0003-2023-2602)
}

\begin{abstract}
$\ddot{\mathbf{O} z}$
Bu çalışmada atık su arıtma sektöründe kullanılan dekantör makinesi için araştırma ve geliştirme çalışmaları yapılmıştır. Çalışma kapsamında atık su arıtma sektöründe kullanılan dekantörlerde helezon tasarımı ve analizi yapılmıştır. Dekantörlerde makine içine alınan ürün, yüksek devirlerde dönerek katı ve sıvı olarak iki veya daha fazla faza ayrılır. Katı fazın susuzlaştırılıp dışarıya taşınması için helezon ile tambur farklı açısal hızlar ile dönmektedir. Makinede yüksek devirlerde dönen iki rotorun bulunması, helezonun asimetrik yapıda olması ve içeriye alınan ürünün homojen dağılmaması gibi nedenlerden dolayı helezon yapraklarına kuvvetler uygulanmaktadır. Tasarım için öncelikle makine içerisine alınan karışımın hareketini modelleyen matematiksel eşitlikler ile tambur ve helezona gelen yükler belirlenmiştir. Farklı yaprak kalınlığına sahip helezonların sonlu elemanlar yöntemini temel alan analiz programı ANSYS kullanılarak dayanımı belirlenmiş̧tir. Helezon yaprak kalınlıkları farklı alınarak her bir tasarım için gerilme grafikleri elde edilmiştir. Ayrıca her bir yaprak kalınlığı için emniyet katsayı değerleri belirlenmiştir. Emniyet katsayısı sonuçları değerlendirildiğinde yaprak kalınlığının olması gereken minimum değeri belirlenmiştir. Bu durumda maksimum eşdeğer gerilme değeri belirlenmiştir.
\end{abstract}

Anahtar kelimeler: Dekantör, helezon tasarımı, sonlu elemanlar analizi, gerilme analizi.

\section{Finite Element Analysis of Centrifugal Decanter Screw}

\begin{abstract}
In this study, research and development studies were carried out for decanter machine used in waste water treatment sector. In the scope of the study, spiral design and analysis of decanters used in waste water treatment sector were performed. In the decanter, the product, which was taken into the machine, rotates at high speeds and was divided into two or more phases as solid and liquid. The spiral and the drum rotated at different angular speeds to dewater and transport the solid phase to the outside. For reasons such as the presence of two rotors rotating at high speeds in the machine, the spiral being asymmetric and the homogeneous distribution of the product inside, forces were applied to the spiral leaves. For the design, the mathematical equations that model the movement of the mixture taken into the machine and the loads to the drum and the helix were determined. The strength of the spirals having different leaf thicknesses was determined by using ANSYS which was based on finite element method. Stretch plots were obtained for spiral leaves by taking different spiral leaves. When the safety coefficient results are evaluated, the minimum value of the leaf thickness must be determined. In this case, the maximum equivalent stress value has been determined.
\end{abstract}

Keywords: Decanter, design of screw, finite element analysis, stress analysis.

\section{Giriş}

Dekantör santrifüj, katı-sıvı, sıvı-sıvı karışımların ayrılmasında kullanılır. Makine; elemanları taşıyan gövde, yüksek hızlı dönen tambur, tamburdan farklı hızda dönen helezon ve hız farkını ayarlayan tahrik grubundan oluşmaktadır. Besleme borusuyla ayrılacak olan ürün dekantöre alınır ve üzerine uygulanan merkezkaç kuvveti etkisi ile tambur yüzeyine doğru özgül ağırlıklar farkıyla birbirinden ayrılır. Tambur

\footnotetext{
*Sorumlu yazar: gozde.deger@cbu.edu.tr

Geliş Tarihi: 18.09.2020, Kabul Tarihi: 08.04.2020
} 
ile helezon farklı açısal hızla hareket etmektedir. Böylelikle tambur duvarlarına çöken katı, helezon vasıtasıyla konik kısma taşınır ve burada susuzlaştırılarak ürün alınır. Sıvı faz, katı fazın çıkış yönünün tersine helezonun oluşturduğu helisel yoldan ilerleyerek seviyesi ayarlanabilir plakalardan ürün tahliye edilir.

Çevre sektöründe kullanılacak dekantörün tasarımında iki ana hedef vardır. Birincisi çıkan katının nemsiz, diğeri ise sıvının berrak olmasıdır. Bell vd., 2014, dekantör tasarımında ürün kalitesini etkileyen önemli parametreleri belirlemişlerdir. Bunlar katı ve sıvı yoğunluğu, açısal hız, katı kütle oranı, katı ve sıvı çıkış yarıçapları, helezon hatve uzunluğu, helezon yaprak açısı, konik ve silindirik bölüm uzunluğu, sürtünme katsayısı, koniklik açısı ve diferansiyel hızdır. Ek olarak, helezonun konik bölgesinde taşınan katının helezon yapraklarına uyguladığı kuvvet ve katı kütlenin iletimi için gereken gücü hesaplamışlardır. Helezon geometrik özellikleri, katı çıkış yarıçapı gibi makine parametrelerinin, helezonun katıyı taşıması için harcadığı güce etkisi gösterilmiştir. Helezonun yaprak açısı azaltıldıkça gereken güç artmaktadır. Bu artışın eğimi sürtünme katsayısının artışıyla büyümektedir. Katı çıkış yarıçapı arttırıldıkça gereken güç azalırken, relatif yoğunluk artırıldıkça gereken güç artmaktadır [1]. Bizard vd, 2013, santrifüj kuvvet etkisi altındaki katının nem dengesi ile ilgili bir formül geliştirmişlerdir. Makalelerinde tarif ettikleri Bond sayısı; sıvı yoğunluğu, partikül çapı, açısal hız, katı çıkış yarıçapı ve yüzey gerilimine bağlıdır ve kılcallık sayısının hesaplanması esasına dayanır. Bond sayısı 30'un üzerinde ise katı çıkışındaki nem dengesi minimize edilmiş demektir [2]. Dong vd., 2014, ise besleme hızı ile makine boyutları arasında ilişki kuran sigma teorisini geliştirmişlerdir. Dekantörün besleme hızı; Bond sayısı, sıvı çıkış yarıçapı, relatif yoğunluk, silindir boyu, katı çıkış yarıçapı, yüzey gerilimi, sıvının vizkozitesi ve silindirik tamburun iç yarıçapına bağlıdır [3].

Dekantörlerde en önemli parçalar diferansiyel hız farkı ile dönen tambur ve helezondur. Bu parçalardaki dengesiz kütleler santrifüj kuvveti etkisi ile titreşime neden olmaktadır. Liu vd., 2015, ANSYS Fluent, Static Structural yazılımı kullanarak dekantör tamburunun içindeki akışkan-katı etkileşimini incelemişlerdir. Akışkan yapının yoğunluğuna bağlı olarak ortaya çıkan gerilmeleri elde etmişlerdir. Santrifüj ve hidrostatik basıncın helezon üzerindeki etkileri ve bu etki neticesinde tasarımda kritik bölgeler elde edilmiştir [4]. Zheng vd., 2009, yine Fluent kullanarak tambur içindeki akışkanın basınç ve hız diyagramlarını elde etmişlerdir [5]. Wang vd., 2010, ANSYS kullanarak helezon yapraklarının ve konik açısının tasarıma etkilerini incelemişlerdir [6].

Liu vd, 2007, helezon için statik ve titreşim analizi yapmışlardır [7]. Yang vd., 2008, Solidworks Simulation programını kullanarak helezonun farklı çap, rotasyonal hız, yaprak kalınlığı ve diğer tasarım parametreleri için statik ve modal analiz yapmışlardır [8]. Domanski ve Zywica, 2007, basınçlı kabın tasarımı için çeşitli tasarımlar yapmış ve optimize etmişlerdir [9]. Ahmed vd., 2014, çalışmalarında yeni basınçlı kap tasarımları sunmuşlardır. İç basınç altında olan bu tasarımlar, sonlu elemanlar yöntemiyle analiz edilmiş ve sonuçlar değerlendirilmiştir [10].

Bu çalışmada atık su arıtma sektöründe kullanılan dekantör makinesi için araştırma ve geliştirme çalışmaları yapılmıştır. Sanayimizde mevcut olarak üretilmekte olan dekantörün yapraklarına gelen kuvvetler referans verilen bir makaleden yararlanılarak belirlenmiştir. Helezon yapraklarına uygulanan kuvvet neticesinde yapraklarda meydana gelen gerilmeler nümerik olarak elde edilmiştir. Helezonun yaprak kalınlığına göre değişen gerilme değerleri grafik halinde sunulmuştur. Tasarım ve yüklemeler için elde edilen emniyet katsayısı hesaplanmış ve olması gereken minimum helezon yaprak kalınlığı belirlenmiştir.

\section{Materyal ve Metot}

\subsection{Santrifüj Dekantör Helezonunun Modellenmesi ve Gerilme Analizi}

\subsubsection{Santrifüj Dekantörün Çalıșma Prensibi}

Santrifüj dekantörler; katı-sıvı karışımlarının ayrıştıılmasında, katı-sıvı karışımların susuzlaştırılmasında, konsantre edilmesinde, sınıflandırılmasında ve bileşenlerin ayrıştırılmasında kullanılmaktadır. Dekantörde ürün ayrıştırma şeması Şekil 1'de verilmiştir. 


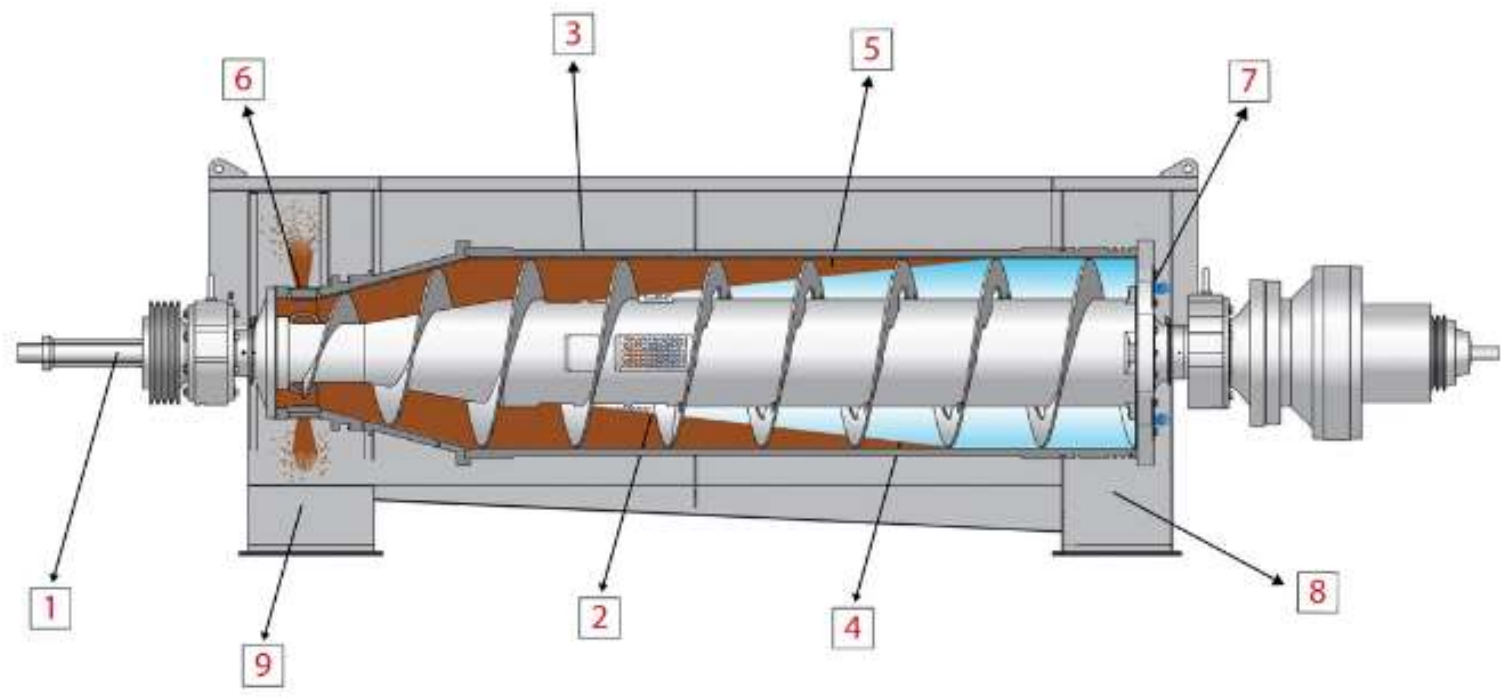

1. Orun Giriş Borusu 2. Urun Besleme haznesi 3. Tambur 4. Helezon 5. Separasyon Haznesi 6. Katı Çikış Burcu

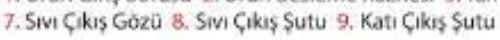

Şekil 1. Bir santrifüj dekantörün şematik gösterimi [11]

Şanzıman; hem tek hem de çift motorlu dekantör sisteminde kullanılan ve dekantörün ürün taşımasında görev alır. Konik kesimde ürün, besleme borusundan girdikten sonra santrifüj etkisi altında kalır. Helezon yardımı ile konik kesime doğru ürün kaydırılır. Ürün içerisinde yoğun olan fazlar bu kısımda birikir ve ürün dışarıya bırakılır. Silindirik bölüm santrifüj etkinin olduğu en önemli bölümdür. Ürünlerin yoğunluk farkından dolayı ayrışmaya başladığı bölümdür. Berraklaştırılmış sıvı havuz, santrifüjde, yoğun fazdan ayrıştırılan kısımdır ve devamında sıvı atık kısmında ürün alınır. Katı atıklar konik kısımdan sonra ayrıştırılarak yoğun fazlı ürün dışarı alınır. Ürünün ayrıştııılmasından sonra ortaya çıkan yoğun faz, bazı uygulamalarla yoğun fazın parçacıkları birbiri ile birleşip katılaşmış tortu haline gelebilmektedir. Hafif faz ürünü olan; sıvı atıklar da makinenin diğer ucundan elde edilir. Çamur, ürün giriş borusu yardımı ile beslenir; bu sırada çamur serbest bırakılır ve santrifüj kuvveti ile katılar haznenin dış kısmı boyunca yerleşir.

\subsubsection{Helezonun Modellenmesi}

Helezonun yapraklarının tasarımını konu alan bu çalışma için yapraklar üzerine gelen kuvvetlerin bilinmesi gerekmektedir. Yaprak geometrilerinin belirlenmesi, tasarımın düşük maliyete sahip olması açısından önemlidir.

Bell vd., 2014, çalışmalarında dekantör güç tüketimini konu alan çalışma yapmışlardır. Bu çalışmada; helezon yaprakları üzerine gelen kuvvetleri matematiksel model kurarak elde etmişlerdir [1]. Dekantör parametrelerine bağlı elde edilen denklemden yararlanılarak yapraklara gelen eksenel kuvvet belirlenmiştir. "Konik kesit boyunca ilerleyen diferansiyel katının serbest cisim diyagramı Şekil 2'de gösterilmiş̧tir. Hem x- $\theta$ hem de $\mathrm{x}$-r düzlemleri için iki boyutlu serbest gövde diyagramları sunulmuştur. Silindirik koordinatlar, dönme ekseni boyunca yönü, çevresel yönde $\theta$ (tambur ve kaydırma yönünde pozitif) ve dönüş ekseninden radyal olarak kullanılır. Model, çevresel genişlik $r \theta$, eksenel kalınlık $\delta x$ ve derinlik $r_{o x}-r_{i x}$ 'in yerleşik katı parçalarının sabit ivmeli hareketini göz önüne alır. Birim eleman, açısal hıza sahip olan tambur ile birlikte dönmekte ve $\omega^{+} \Delta$ hızında dönen bir adım G'ye ait bir helezon tarafindan eksenel olarak taşınmaktadır. $\mathrm{G}$ ise herhangi bir cismin üzerinde bulunan çekim ivmesidir" [1]. 

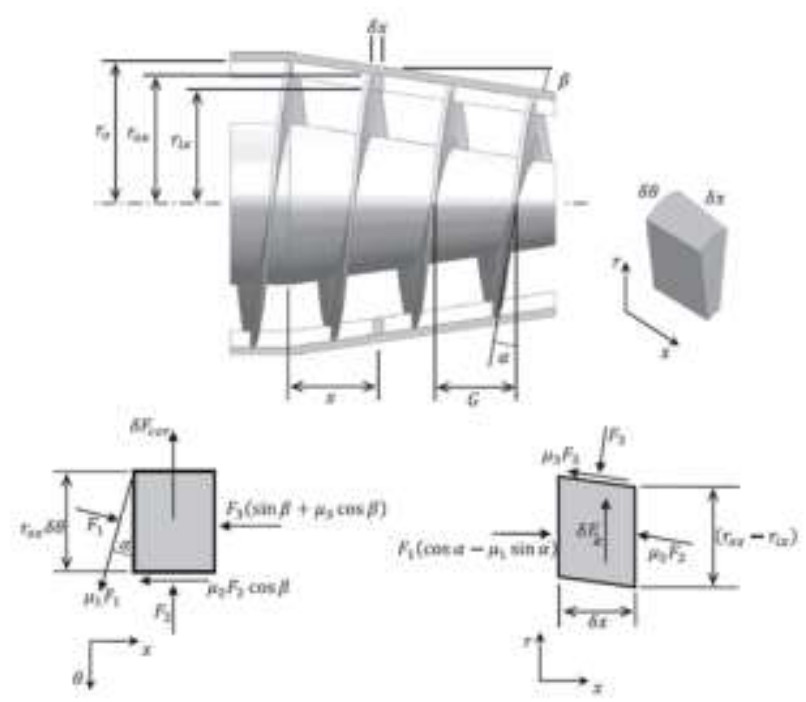

Şekil 2. Konik kısımda bulunan yoğun fazın etkisi ve serbest cisim diyagramı [1]

"Helezon yaprakları üzerinde bulunan diferansiyel eleman, hem dış çapa doğru hareket etmekte hem de açısal hızla dönmektedir. Bu nedenle eleman üzerinde koriolis kuvveti oluşmaktadır" [1].

$$
" \delta F_{k o r}=2 \frac{d r}{d t} \omega \delta m=-\frac{G \Delta}{\pi} \omega \tan \beta \delta m "
$$

“Şekil 3'te bulunan serbest cisim diyagramı için denge denklemleri, belirtilen $\mathrm{r}, \theta$ ve $\mathrm{x}$ boyutları için ayrı ayrı yazılarak üç eşitlik elde edilir" [1].

$$
\begin{gathered}
" F_{1}\left(\cos a-\mu_{1} \sin a\right)=F_{2} \mu_{2}+F_{3}\left(\sin \beta++\mu_{3} \cos \beta\right) " \\
" F_{1}\left(\sin a+\mu_{1} \cos a\right)=F_{2}+\delta F_{k o r .} . \\
" \delta F_{3}=\delta F_{k} \cos +F_{1} \sin \beta\left(\cos a-\mu_{1} \sin a\right) "
\end{gathered}
$$

“Denklem (2), (3) ve (4) kullanarak $F_{1}$ kuvveti elde edilir" [1].

$$
\text { " } F_{1} \frac{\left[\left(\sin \beta+\mu_{3} \cos \beta\right) \delta F_{c}-\mu_{2} \delta F_{k o r}\right] \cos \beta \sec a}{\left(1-\mu_{1} \tan a\right)\left[1-\sin \beta\left(\sin \beta+\mu_{3} \cos \beta\right]-\mu_{2} \cos \beta\left(\tan a+\mu_{1}\right)\right.} "
$$

Tablo 1'de atık su arıtma dekantörüne ait parametre değerleri verilmiştir. Bu parametreler kullanılarak, konik kesit boyunca ilerleyen diferansiyel katının serbest cisim diyagramı üzerine gelen kuvvetler hesaplanmıştır (Şekil 2). Bu kuvvetler; dekantör içinde bulunan ürünün helezon yapraklarına normal yönden uyguladığı ve ürünün helezona karşı tepki kuvveti $F_{1}$, denge anında belirtilmiş katı ürün ile helezon malzemesi arasındaki sürtünme kuvveti $\mathrm{F}_{2}$, kat1 maddenin tamburun üst yüzeyinde birikmesinden dolayı elamana tambur yüzeyinin uyguladığı tepki kuvveti $F_{3}$ ve koriolis kuvveti $F_{\text {kor }}$ 'dur [1]. Bu kuvvet değerleri Tablo 2'de yazılmıştır. 
Tablo 1. Santrifüj Dekantörün Helezonuna Ait Yapısal Parametreler

\begin{tabular}{r|cc}
\hline Parametreler & Semboller & Değerler \\
Helezon dış yarıçapı & $\mathrm{r}_{\mathrm{i}}$ & $74.50 \mathrm{~mm}$ \\
Silindirik bölümün uzunluğu & $\mathrm{L}_{\text {silindir }}$ & $1260 \mathrm{~mm}$ \\
Konik bölümün uzunluğu & L $_{\text {konik }}$ & $460 \mathrm{~mm}$ \\
Koniklik açısı & $\beta$ & 140 \\
Yaprak açısı & $\alpha$ & 6.800 \\
Katı fazın kütlesel debisi & $\dot{m}_{\boldsymbol{k}}$ & $6 \mathrm{~m} 3 / \mathrm{h}$ \\
oranı & $\mathrm{n}$ & 0.01 \\
Ağır fazın taneciklerinin bosluk & & \\
Sürtünme katsayıları & $\mu_{1}, \mu_{2}, \mu_{3}$ & 0.20 \\
Helezonun açısal hızı & $\infty$ & $365.40 \mathrm{rad} / \mathrm{s}$ \\
Diferansiyel hız fark1 & $\Delta$ & $1.04 \mathrm{rad} / \mathrm{s}$ \\
\hline
\end{tabular}

Tablo 2. Santrifüj Dekantörün Helezonuna Etki Eden Kuvvetler

\begin{tabular}{r|cc}
\hline Kuvvetler & Semboller & Değerler \\
\hline $\begin{array}{r}\text { Helezon Yaprağına Gelen Normal } \\
\text { kuvvet }\end{array}$ & $\mathrm{F}_{1}$ & $7642 \mathrm{~N}$ \\
$\begin{array}{r}\text { Sürtünme kuvveti } \\
\text { Tamburun yüzeyinin katı faza } \\
\text { maruz kalabileceği kuvvet }\end{array}$ & $\mathrm{F}_{2}$ & $230 \mathrm{~N}$ \\
Koriolis kuvveti & $\mathrm{F}_{3}$ & $17165 \mathrm{~N}$ \\
\hline
\end{tabular}

\subsubsection{Hesaplamalı Analiz Modeli}

Dekantöre ait yapısal dayanıklılığı incelemek için hesaplamalı analiz modeli kullanılmıştır. Denklemlere ait sayısal çözümü elde etmek için ticari bir yazılım olan ANSYS 17.2 programının yapısal analiz modülünden yararlanılmıştır. Programda "metric m, kg, N, s, V, A" birimleri kullanılmıştır. Yapıları matematiksel modele dönüştürmek için süpürme yöntemi ile ağ örgüsü yapılmıştır. Süpürme yöntemi SOLSH190 ve SOLID 186 elemanlara sahiptir. Katı yapılar için tercih edilen elemanlardır. Bu çalışmada yapı, SOLID 186 yapısal eleman tipleri ile oluşturulmuştur. SOLID 186 elemanı üç boyutlu kuadratik şekil fonksiyonlarına sahip ve 20 dügüm noktası içeren bir elemandır. Bunun sebebi, et kalınlığı boyunca en az iki elemanın konumlandırılabilmesidir. Her bir düğüm noktasında öteleme yönünde $\mathrm{x}$, y ve z olmak üzere üç serbestlik derecesine sahiptir. Helezonun sonlu elemanlara ait sayısal ağ modeli Şekil 3’te verilmiştir. Oluşturulan model 561158 düğüm noktası ve 145682 elemandan oluşmaktadır. Analiz 64GB Ram ve 4 çekirdeğe sahip bilgisayar ile yapılmıştır.

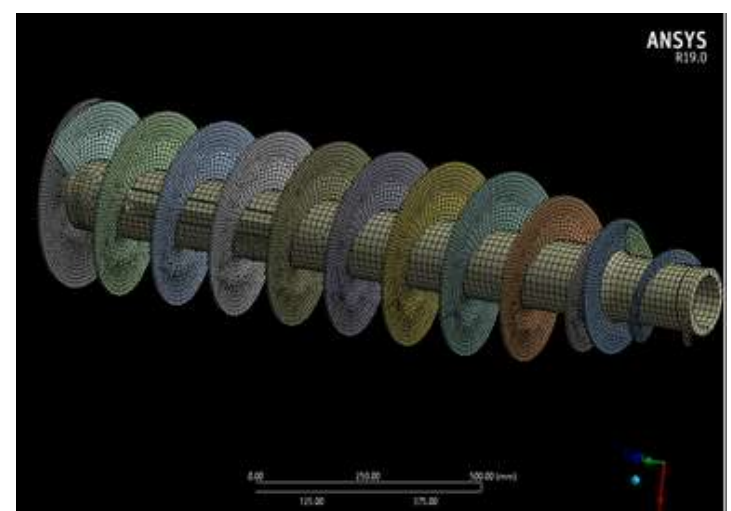

Şekil 3. Dekantöre ait sonlu elemanlar modeli sayısal ağı 


\subsubsection{Malzeme Bilgisi}

Helezon yaprak ve borusu DIN 1.4401 malzemesinden üretilmektedir. Yapısal analizlerde kullanılan malzeme özellikleri olan elastisite modülü $193 \mathrm{GPa}$, poisson oranı 0.29, özkütle $8 \mathrm{gr} / \mathrm{cc}$, akma sınırı 290 MPa'dır.

\subsubsection{Helezonun Yapraklarına Eksenel Kuvvet Yüklemesi}

Helezonun yapraklarına gelen eksenel yükleme, yoğun fazın özkütlesine ve yaprak açılarına bağlıdır. Parametrik olarak yazılan Denklem (5)'te Tablo 1'deki özellikler girilerek eksenel kuvvet elde edilmiştir. Eksenel kuvvet $7642 \mathrm{~N}$ elde edilmiştir. Şekil 4'te yaprak kalınlığının parametreye bağlı olarak arttırılması için seçilen yüzey ve koordinat gösterilmiş̧ir.

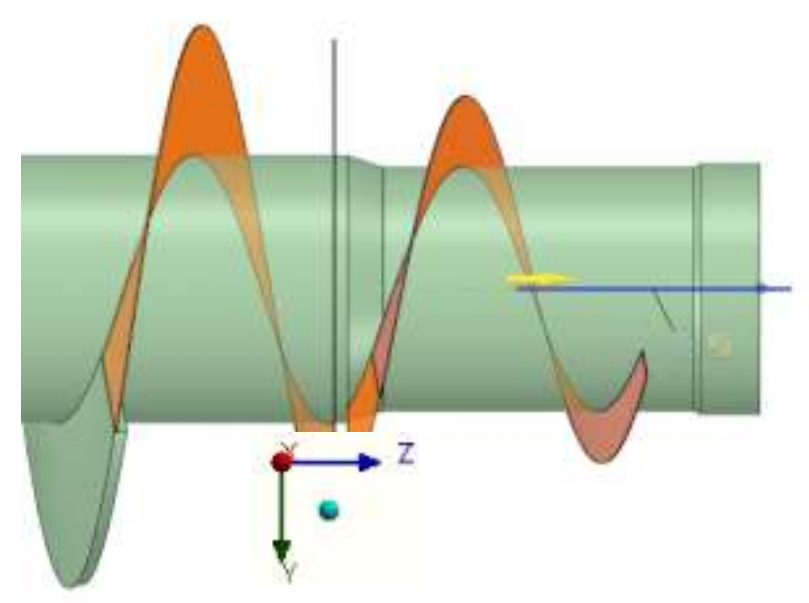

Şekil 4. ANSYS SpaceClaim yazılımının parametreye bağlanan yüzeyi

Tablo 3 'te helezon yaprak kalınlığına bağlı olarak toplam yaprak kütle değerleri yazılmıştır. Helezonlara uygulanan sınır şartları Şekil 5 'te gösterilmiştir. A ucundan sabitlenen helezona 365.47rad/s açısal hız uygulanmıştır. Helezon yapraklarına ise eksenel yönde $7642 \mathrm{~N}$ uygulanmıştır.

Tablo 3. Helezon yaprak kalınlıklarında parametreye verilen giriș değerleri

\begin{tabular}{c|c}
\hline $\begin{array}{c}\text { Helezon yapraklarının } \\
\text { toplam kütlesi }[\mathrm{kg}]\end{array}$ & $\begin{array}{c}\text { Helezonun yaprak } \\
\text { kalınlığ }[\mathrm{mm}]\end{array}$ \\
\hline 27 & 4 \\
34 & 5 \\
41.10 & 6 \\
48.20 & 7 \\
56.30 & 8 \\
63.40 & 9 \\
70.50 & 10 \\
77.60 & 11 \\
84.70 & 12 \\
\hline
\end{tabular}




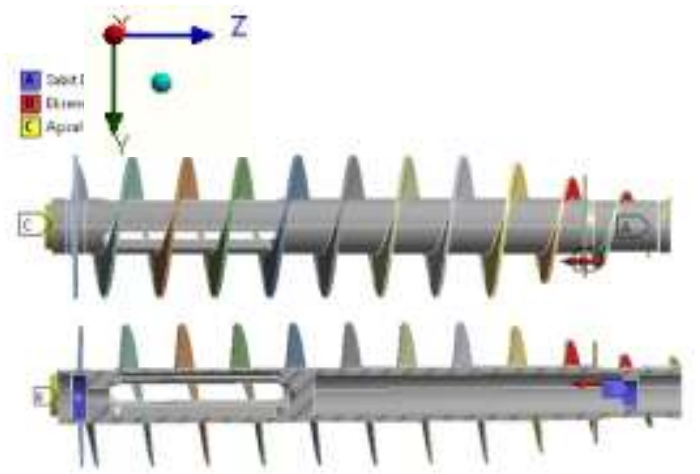

Şekil 5. Helezonun eksenel yükleme ve sınır koşulu

\section{Bulgular}

Hesaplamalı analizler ANSYS paket programı ile yapılmıştır. Helezona etki eden eksenel kuvvet, özellikle yoğun fazın olduğu kısımda (konik bölüm) artmaktadır. Tablo 4'te helezon yaprak kalınlığına bağlı olarak gerilme sonuçları ve emniyet katsayıları verilmiştir. Helezonun tasarımında, yaprak kalınlığı iyileştirilmediği durumda hem dengesiz kütle artmakta hem de doğal frekans azalmaktadır. Bunun sonucunda da maliyet yükselmektedir. Burada emniyet katsayı değeri sınır olarak 2 olarak belirlenmiştir. Bu durumda helezonun yaprak kalınlığı minimum $9 \mathrm{~mm}$ olması gerekmektedir. Helezon yaprak kalınlığ $12 \mathrm{~mm}$ seçilmesi durumunda ise emniyet katsayısı 14.5 olarak hesaplanmıştır. Şekil 6'da farklı helezon yaprak kalınlığına göre gerilme değerlerinin değişimi görülmektedir. Şekil 7'de ise farklı helezon yaprak kalınlığına göre emniyet katsayı değerleri görülmektedir. Helezon yaprak kalınlığı arttıkça gerilme değeri azalmakta ve dolayısı ile emniyet katsayısı artmaktadır.

Tablo 4. Helezon yapraklarının kalınlığına bağlı olarak gerilme değerleri

\begin{tabular}{c|cc}
\hline $\begin{array}{c}\text { Helezon yaprak } \\
\text { kalınlı̆̆ } 1 \mathrm{~mm}]\end{array}$ & $\begin{array}{c}\text { Maksimum } \\
\text { Eşdeğer Gerilme } \\
\text { Değeri [MPa] }\end{array}$ & $\begin{array}{c}\text { Emniyet } \\
\text { katsayıs1 }\end{array}$ \\
\hline 4 & 632 & 0.45 \\
5 & 590 & 0.49 \\
6 & 462 & 0.63 \\
7 & 340 & 0.85 \\
8 & 150 & 1.93 \\
9 & 115 & 2.52 \\
10 & 85 & 3.41 \\
11 & 69 & 4.21 \\
12 & 20 & 14.5 \\
\hline
\end{tabular}

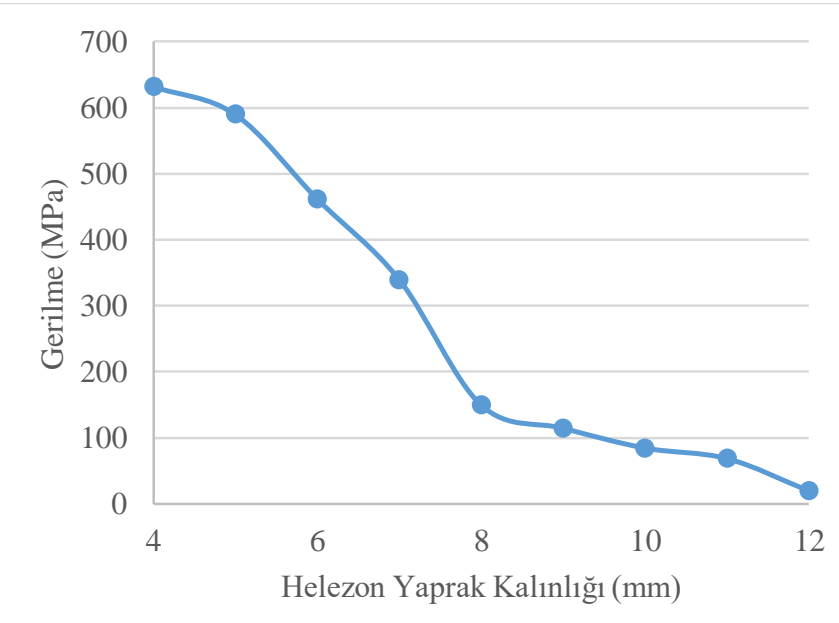

Şekil 6. Farklı helezon yaprak kalınlığı - gerilme değerleri 


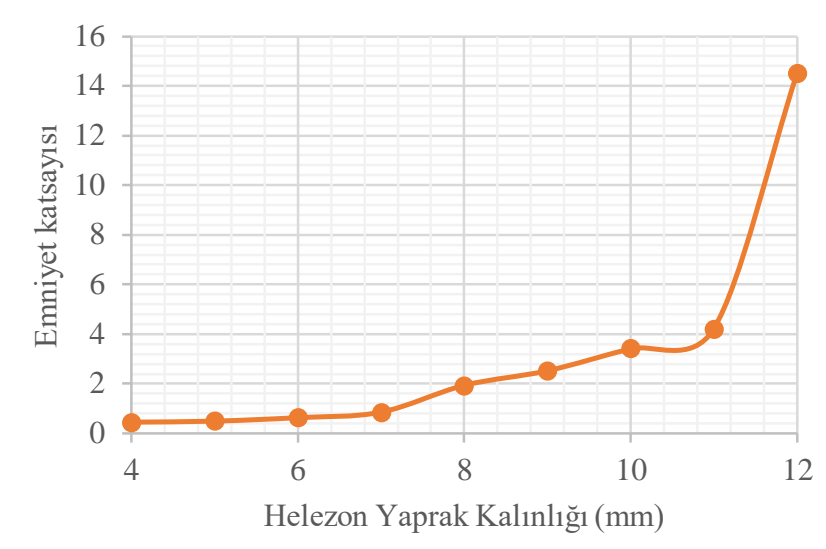

Şekil 7. Farklı helezon yaprak kalınlığı - emniyet katsayısı değerleri

\section{Tartışma ve Sonuç}

$\mathrm{Bu}$ çalışmada dönen elemanlara sahip olan dekantör makinesinin helezonunun tasarımı ve gerilme analizi üzerine çalışılmıştır. Çalışma, Türkiye Aydın ilinde faaliyet gösteren dekantör makineleri üreticisi HAUS Makine Sanayi AŞ’nin atık su arıtma modelinin helezonun geliştirilmesine yönelik öneriler sunmaktadır. Asimetrik yapıya sahip olan helezon yüksek devirlere çıkıldığında titreşim sorunu meydana gelmektedir. Helezon yapraklarının ideal olarak modellenmesi titreşim problemindeki dengesiz kütle miktarını azaltacağı gibi aynı zamanda maliyetten de tasarruf sağlayacaktır. Literatürde geliştirilmiş olan matematiksel modeller yardımı ile dönme etkisindeki helezonun yapraklarına etki eden kuvvetler hesaplanmıştır. Helezon yaprak kalınlık değerlerine göre gerilme değerleri ve emniyet katsayıları elde edilmiş̧ir. Makinenin mekanik analizleri sonlu elemanlar yöntemini kullanan hesaplamalı analiz programı olan ANSYS kullanılarak gerçekleştirilmiştir.

Helezon yaprak kalınlığının minimum değerinin $9 \mathrm{~mm}$ olması gerekmektedir. Bu durumda emniyet katsayısı 2.52'dir. Mevcut makinede kullanılan yaprak kalınlığ $12 \mathrm{~mm}$, emniyet katsayıs1 14.5 'tir. Emniyet katsayısı minimum 2 alınması durumunda mevcut tasarıma göre helezon yapraklarının toplam kütlesi \% 25 azaltılmıştır. Asimetrik yapıya sahip olan helezonun kütlesindeki bu azalma dengesiz kütle miktarını azaltacak, böylelikle titreşim genliklerinin azalmasını sağlayacaktır. Aynı zamanda sistemin tabi frekansı artacaktır. Böylelikle makine daha yüksek devirlerde çalışabilecektir.

$\mathrm{Bu}$ çalışma her bir helezon yaprak kalınlığı için meydana gelen gerilme değerlerini ve hesaplanan emniyet katsayı değerlerini sunmaktadır. Böylelikle dekantör tasarımcılarına fikir verebilecek bir çalışma gerçekleştirilmiştir. Gelecekte önerilen tasarım için doğal frekans analizi yapılabilir.

\section{Yazarların Katkısı}

Gözde SARI, Ahmet Alper AKIŞ ve Gökhan ÜĞÜDÜCÜ çalışmanın konseptine, çalışma için verilerin toplanmasına ve analiz edilmesine katkıda bulunmuşlardır. Gözde SARI ve Ahmet Alper AKIŞ literatür taramasını yapmışlardır. Gözde SARI, Gökhan ÜĞÜDÜCÜ ve Ahmet Alper AKIŞ katı modeli ve sınır şartlarını belirlemişlerdir. Ahmet Alper AKIŞ sonlu elemanlar analizini yapmıştır. Gözde SARI, Ahmet Alper AKIȘ ve Gökhan ÜĞÜDÜCÜ yapılan analizi ve sonuçlarını inceleyip yorumlamışlardır. Gözde SARI ve Ahmet Alper AKIŞ makale yazımını gerçekleştirmişlerdir. Gözde SARI, Ahmet Alper AKIŞ ve Gökhan ÜĞÜDÜCÜ makaleyi kontrol etmişler ve makale son haline getirilmiştir. Gözde SARI makalenin değerlendirilme aşamasındaki yazışmaları gerçekleştirmiş ve düzeltmeleri Ahmet Alper AKIŞ ile birlikte yapmıştır.

\section{Çıkar Çatışması Beyanı}

Yazarlar arasında herhangi bir çıkar çatışması bulunmamaktadır. 


\section{Araştırma ve Yayın Etiği Beyanı}

Yapılan çalışmada araştırma ve yayın etiğine uyulmuştur.

\section{Kaynaklar}

[1] Bell G.R.A., Symons D.D., Pearse J.R. 2014. Mathematical Model for Solids in a Decanter Centrifuge. Chemical Engineering Science, 107: 114-122.

[2] Bizard A.F.M., Symons D.D., Fleck N.A. Grimwood G.C. 2013. Design Guidelines for Granular Particles in a Conik Centrifugal Filter. Chemical Engineering Research and Design, 91 (2): 348360.

[3] Dong L.D., Fu S.C., Yuan H.X. 2014. Numerical Simulation on Pressure Field in a Decanter Centrifuge. Chemical Industry and Engineering Progress, 33 (2): 309-336.

[4] Liu H., Li P., Xiao H., Mu W. 2015. The Fluid Solid Coupling Analysis of Screw Conveyor in Drilling Fluid Centrifuge Based on Ansys. Petroleum, 1 (3): 251-256.

[5] Zheng S.F., Ren X., Xie L.J. 2009. Numerical Simulation of Flow Field in Decanter Centrifuge. Light Industry Machinery, 27 (6): 26-29.

[6] Wang L.Q., Chen T., Wu D.Z. 2010. Structural Strength Parameterized Analysis of Horizontal Decanter Centrifuge Conveyor. Journal of Mechanical Design, 27 (5): 67-70.

[7] Liu A.J., Fu C.M. 2007. Static Finite Element Screw Conveyor to a Horizontal Centrifuge Analysis. Journal of Design Research, 34 (3): 26-28.

[8] Yang J., Preidikman S., Balaras E.A. 2008. Strongly Coupled, Embedded-Boundary a Method for Fluid Structure Interactions of Elastically Mounted Rigid Bodies. Journal of Fluid Structure, 24 (2): 167-182.

[9] Domanski J., Zywica G. 2007. Optimization of the construction of a pressure tank using CAD/CAE systems. Technical Sciences, 10: 41-58.

[10] Ahmed M., Khan R.U., Badshah S., Jan S. 2014. Finite Element Investigation of Geometry Effect on Pressure Vessel under Combined. International Journal of Engineering and Advanced Technology, 4 (2): 2249-8958.

[11] https://www.haus.com.tr/ (Erişim Tarihi: 11.09.2020). 